\title{
EDUCAÇÃO SEXUAL: PROBLEMAS DE CONCEITUAÇÃO E TERMINOLOGIAS BÁSICAS ADOTADAS NA PRODUÇÃO ACADÊMICO-CIENTÍFICA BRASILEIRA
}

\author{
MARY NEIDE DAMICO FIGUEIRÓ *
}

FIGUEIRÓ, M.N.D. Educação sexual: Problemas de conceituação e terminologias básicas adotadas na produção acadêmico-científica brasileira. Semina: Ci. Sociais/Humanas, v. 17, n. 3, p. 286-293, set. 1996.

RESUMO: Com o objetivo de elaborar o estado do conhecimento da produção acadêmico-científica da Educação Sexual no Brasil, do período de 1980 a 1993, foi realizada a análise de Dissertações, Teses, livros, artigos de periódicos e trabalhos apresentados em eventos. Uma das preocupações foi investigar quais as terminologias básicas adotadas para referir-se ao trabalho de Educação Sexual e quais os conceitos de Educação Sexual presentes nas publicações. Detectou-se a falta de padronização de uma terminologia básica e de uma posição teórica clara e objetiva quanto ao conceito de Educação Sexual. Além disso, diferenças, incoerências elou confusões foram ainda encontradas, em alguns textos, nas tentativas de classificação dos tipos de Educação Sexual. São apresentados subsídios teóricos que direcionam para uma padronização da terminologia básica, conceituação e classificação uniformes $e$ cientificamente válidas.

\section{PALAVRAS-CHAVE: Educação Sexual; conceituação de Educação Sexual; terminologia básica;} Estado da Arte.

\section{INTRODUÇÃO}

Como parte de uma pesquisa mais ampla, que procurou analisar toda a produção acadêmico-científica brasileira sobre Educação Sexual do período de 1980 a 1993 (FIGUEIRÓ, 1995) percebeu-se, já nas leituras preliminares, que vários termos estavam sendo usados como sinônimos ou em substituição ao termo Educação Sexual. Entre eles, citam-se: orientação sexual, informação sexual, instrução sexual, etc.

Esse quadro parecia complicar-se ainda majis, quando distorções e incoerências também foram identificadas, entre vários autores, nas tentativas de conceituação de Educação Sexual e/ou orientação sexual, ou de outras terminologias relacionadas. Acrescese a isso as divergências quanto à classificação dos tipos de Educação Sexual.

Acreditando que as lacunas ou distorções referentes à terminologia básica adotada, à conceituação $e$ à classificação pudessem comprometer, sobremaneira, a qualidade da produção científica e interferir no avanço do corpo teórico desta área do conhecimento, procurou-se fazer uma análise aprofundada das referidas questões.

Tendo participado do V Congresso Brasileiro de
Sexualidade Humana, ocorrido em São Paulo, no período de 16 a 20 de maio de 1995, ficaram mais fortemente ratificadas, para a autora, a urgência e a relevância das reflexões que a seguir serão apresentadas. Além de constatar, mais uma vez, a ausência de uma terminologia comum (uns usavam educação sexual e outros, orientação sexual), uma situação peculiar chamou a atenção: um dos elementos da platéia, em uma determinada conferência, comentou que o termo educação sexual deveria ser abolido e defendia o uso de orientação sexual. Um outro profissional da platéia levantouse dizendo que apoiava a necessidade da abolição do termo e destacou o "brilhantismo" da idéia.

No mesmo evento, um pôster estava sendo exposto e folhetos (BERLER, 1995) entregues, com o objetivo de divulgar a implantação de um Programa de "Educação Afetivo Sexual". Esta terminologia viria, então, para aumentar ainda mais a listagem dos termos adotados em substituição e/ou como sinônimo do termo Educação Sexual.

Foram estas constatações, num evento tão significativo para a temática aqui tratada, que levaram a autora do presente artigo à determinação pessoal de empenho para a divulgação, mais ampla, através de periódico, de suas reflexões já elaboradas sobre a questão.

* Docente/Adjunto do Departamento de Psicologia Social e Institucional da UEL.

Mestre em Psicologia Escolar pela USP de São Paulo. 


\section{PROCEDIMENTO}

Dentre um conjunto de dez Categorias de Análise estabelecidas para avaliar o conjunto da produção acadêmico-científica brasileira, achou-se imprescindível incluir a seguinte: "Questões Conceituais".

Segundo a mesma, em cada publicação que integrava o "corpus", procurava-se investigar: como o autor define Educação Sexual (se define); qual a terminologia que usa: educação sexual ou orientação sexual (ou outra); se estabelece alguma relação e/ou diferença entre esses termos.

Para assegurar a fidedignidade das avaliações de cada texto que integoru o corpus, ficou determinado que duas psicólogas atuassem como juízas. Assim, além das avaliações feitas pela pesquisadora, cada um delas classificou, individualmente, todos os textos, de acordo com a Categoria acima explicitada (além das outras que compunham a Dissertação como um todo).

\section{RESULTADOS E DISCUSSÃO}

Para análise dos resultados, tornou-se como ponto de referência a forma como foram organizados os gêneros de publicações que compõem o "corpus":

- Grupo A: livros e capítulos de livros.

- Grupo B: artigos, pesquisas e trabalhos apresentados em eventos.

- Grupo C: dissertações e teses.

\subsection{Da terminologia usada e da conceituação de Educação Sexual}

\subsubsection{No Grupo A: livros e capítulos de livros}

Num total de 33 publicações (12 livros e 21 capítulos de livros), o termo educação sexual é usado, de forma exclusiva, em 18 publicações $(54,55 \%)$, enquanto que o termo orientação sexual é usado, exclusivamente, em um único capítulo de livro $(3,03 \%)$, conforme demonstra a Tabela 1.

TABELA 1 - Distribuição das terminologias usadas no Grupo A

\begin{tabular}{lcc}
\hline TERMINOLOGIA & $\mathrm{fi}$ & fri \% \\
\hline educação sexual & 18 & 54,55 \\
orientação sexual & 1 & 3,03 \\
educ. sexual = orient. sexual & 13 & 39,39 \\
educ. sexual = inform. sexual & 1 & 3,03 \\
\hline Total & 33 & 100 \\
\hline
\end{tabular}

Em 13 publicações $(39,39 \%)$ são usados como sinônimos os termos: educação sexual e orientação sexual. Em quatro dessas, apesar do uso dos dois termos, há um predomínio marcante no uso de Educação Sexual. São eles: BARROSO E BRUSCHINI, 1985; BRUSCHINI E BARROSO, 1986; MATARAZZO E MAZIN, 1988 e ORTH, 1991.

Somando esse uso com predomínio, ao uso exclusivo do termo educação sexual, a percentagem se eleva de $54,55 \%$ para $66,66 \%$ nos livros e capítulos de livros, isto é, no Grupo A.

O uso do termo informação sexual, como sinônimo de educação sexual, acontece em apenas um livro (3,03\%): São Paulo (1984). Os autores apresentam os dois conceitos, de acordo com Werebe (1977), e defendem que o papel da escola é o desenvolvimento de programação de informação sexual. Ao longo do texto, usam os dois termos como sinônimos.

Do conjunto de 13 livros e capítulos de livros $(39,39 \%)$ que adotam os termos educação sexual e orientação sexual como sinônimos, em quatro textos, há a preocupação dos autores em diferenciar os termos; porém, apesar disso, usam-se como sinônimos. São eles: CONCEIÇÃO, 1988; RIBEIRO, 1990; SUPLICY, 1990 e SUPLICY, 1988

Nos livros (ou capítulos) acima, excetuando-se o de Ribeiro, a educação sexual é considerada tarefa da família e orientação sexual, tarefa da escola.

No caso do livro de RIBEIRO (1990), esse autor afirma que são "... duas expressões de sentido semeIhante...", mas que "... cada uma delas relaciona-se a uma situação específica." (p. 2). Assim, para esse autor, educação sexual refere-se "... aos processos culturais contínuos desde o nascimento, que de uma forma ou de outra direcionam os indivíduos para diferentes atitudes (...) é dada na família, na escola, no bairro, com os amigos, pela televisão...". Portanto, a terminologia educação sexual é usada para se referir aos processos informais. Por outro lado, orientação sexual é uma "... intervenção institucionalizada, sistematizada, organizada e localizada, com a participação de profissionais treinados..." (p. 3).

Conceituar diferentemente os termos chaves e usá-los como sinônimos pode ser considerado um lapso mais significativo nesse último livro, uma vez que se trata de uma publicação científica que, em sua forma original, corresponde a uma dissertação de mestrado.

Diz ainda RIBEIRO (1990), que a distinção das terminologias "... evita uma superposição de termos, que geram confusão por serem utilizados como sinônimos". (p. 3)

Apesar dessa afirmação e do uso predominante do termo orientação sexual quando se refere a um trabalho sistematizado, o que é coerente com a conceituação dada por ele, no texto, em alguns mo-

O corpus consiste no conjunto de todas as publicações analisadas, que falam sobre Educação Sexual (Teses, Dissertações, artigos de periódicos, trabalhos apresentados em eventos). 
mentos, usa o termo educação sexual no local onde, conforme sua própria definição, deveria ter usado o primeiro termo.

Assim por exemplo diz, na p. 10: "a educação sexual propriamente dita, sistematizada e organizada de forma a ser ministrada na escola..." Também na $p$. 13, diz: "quaisquer tentativas mais efetivas de implantação de educação sexual são desestimuladas..."

Ainda dentro do conjunto de 13 livros (ou cap. de livros) que representam $39,39 \%$ e que usam educação e orientação sexual como sinônimos, é útil registrar que dois deles, EISENSTEIN (1995) e LUCA (1980), acrescentam um terceiro termo como sinônimo, usando os três ao longo do mesmo texto. No primeiro, é acrescentado o termo informação sexual, enquanto que no segundo, é acrescentado instrução sexual.

É interessante observar que no único capítulo de livro onde é usado de forma exclusiva o termo orientação sexual (SUPLICY, 1993), a autora preocupa-se em diferenciá-lo do conceito de educação sexual e passa a usar apenas orientação sexual, pois refere-se ao trabaIho sistemático feito na escola, o que é coerente com sua definição dada no capítulo.

Posição diferente assume a mesma autora, em outras publicações (livros): SUPLICY, 1988 e 1990. Nessas, conforme já comentado, usa os dois termos como sinônimos, embora apresente diferenciação dos mesmos.

É útil registrar o lapso cometido no uso dos conceitos, no capítulo de livro de SILVA (1993), onde define educação sexual como um processo assistemático e orientação como um processo sistemático; no texto total, por referir-se ao processo sistemático, usa, coerentemente com sua definição, o termo orientação sexual. Porém, o título do capítulo é: "Educação sexual nas turmas de $5^{\mathrm{a}}$ a $8^{\mathrm{a}}$ séries do $1^{\circ}$ grau". Segundo a definição do autor, no título, deveria constar a palavra orientação sexual.

\subsubsection{No Grupo B: artigos, pesquisas e trabalhos apresentados em eventos}

Conforme mostra a Tabela 2, num total de 72

TABELA 2 - Distribuição das terminologias usadas no Grupo B

\begin{tabular}{lrr}
\hline TERMINOLOGIA & fi & fri\% \\
\hline educação sexual & 42 & 58,33 \\
orientação sexual & 6 & 8,33 \\
educ. sexual = orient. sexual & 19 & 26,38 \\
\hline Total & 67 & 93,04
\end{tabular}

Cinco publicações referem-se o ensino da sexualidade, sem as terminologias específicas, por isso o total não atingiu $100 \%$. publicações, o termo educação sexual é usado, de forma exclusiva, em 58,33\% (42 publicações), enquanto que o termo orientação sexual é usado, exclusivamente, em 8,33\%, ou seja, em apenas 6 .

Em 26,38\% (19 publicações) são usados ambos os termos, como sinônimos.

Deste último conjunto, apenas em duas, TAVARES (1985) e PIZZATTO (1981), existe a preocupação em diferenciar os termos. Apesar de afirmarem que a educação sexual cabe à família e que para o trabalho feito pela escola deve ser usado o termo orientação sexual, essas autoras adotam ora um termo, ora outro, para se referirem à atuação da escola. Portanto, apesar da diferenciação, usam os termos, confusamente, como sinônimos.

Conceituar diferentemente os termos e usá-los como sinônimos é um problema encontrado em mais três outros textos: HENTSCHEL (1987); MENDES (1984); XAVIER (1985). O que varia apenas é que os termos usados são: educação sexual e informação sexual no primeiro texto e educação sexual e instrução sexual nos dois últimos.

O termo instrução sexual é usado apenas nesses dois textos $(2,77 \%)$ e portanto, não de forma exclusiva, ou seja, é usado conjuntamente com educação ou orientação sexual.

Nas tentativas de definição e/ou diferenciação desses termos-chaves, é possível constatar outras discrepâncias. Assim por exemplo, enquanto para alguns autores, Educação Sexual é o trabalho que cabe à família e orientação ou instrução sexual é o que cabe à escola, para outros, educação sexual é um processo de formação global da pessoa, para o qual pode contribuir tanto a família, quanto a escola e a sociedade de forma geral e a instrução ou orientação sexual são considerados um processo informativo, para o qual podem contribuir também esses mesmos elementos.

No primeiro grupo encontram-se os autores: BERGER (1990); CONCEIÇÃO (1985); CONCEIÇÃO E VITIELLO (1986); PIZZATTO (1981); TAVARES (1985); VITIELLO (1987) e XAVIER (1985).

No segundo grupo: GHERPELLI (1992) e MENDES (1984).

\subsubsection{No Grupo C: Dissertações e/ou Teses}

TABELA 3 - Distribuição das terminologias usadas no Grupo C

\begin{tabular}{lcl}
\hline TERMINOLOGIA & $\mathbf{f i}$ & $\mathbf{f r i} \%$ \\
\hline educação sexual & 7 & 43,75 \\
educ. sexual = orient. sexual & 8 & 50 \\
\hline Total & 15 & 93,75 \\
\hline
\end{tabular}

Duas dissertações referem-se ao ensino da sexualidade, sem as terminologias específicas, por isso o total não atingiu $100 \%$. 
Segundo a Tabela 3, no conjunto de dezessete Dissertações e/ou Teses, o termo educação sexual é usado de forma exclusiva em sete $(43,75 \%)$ dessas publicações: BARCELLOS (1992); CHAGAS (1989); EGRY (1985); FELIZARI (1989); ROCHA (1987); SCHUSSEL (1982) e VERARDO (1989). Dentre este grupo, apenas Schussel e Felizari procuram apresentar a conceituação. SCHUSSEL (1982) elabora de forma pessoal o conceito, que é coerente com o dado por Werebe ${ }^{2}$, embora não faça referência direta ao conceito dessa autora.

Apesar de defender a necessidade da clareza do conceito de educação sexual, FELIZARI (1989) apresenta um elaboração pessoal e pouco objetiva. Começa conceituando educação e para isso pauta-se em dois teóricos, explicitando-os; quando do momento da conceituação de educação sexual, não recorre às conceituações teoricamente já elaboradas, como por exemplo, o conceito apresentado por Werebe.

Felizari assim conceitua educação sexual:

"... consiste em propiciar experiências que auxiliem o ser humano a viver e expressar o amor através do sexo, com a aceitação do papel sexual correspondente. A educação sexual significa muito mais do que a instrução a respeito dos fenômenos da reprodução, vistos como princípios biológicos ou fisiológicos. Significa, na verdade, um processo progessivo de orientação e de exemplo, assim como de informação." (FELIZARI, 1989, p. 30).

Pode ser considerado um conceito limitado, tendo em vista que concebe a educação sexual como um processo unilateral, onde ao educando parece caber apenas um papel de receptor passivo. Não recorrer a conceituações teoricamente já elaboradas é um procedimento que se observa também em outras publicações, sejam elas artigos de periódicos, livros ou mesmo em algumas dissertações e/ou teses.

É possível que essa atitude intertira, negativamente, no avanço científico dessa temática.

Além disso, a omissão da conceituaçaõ de educação sexual, em casos onde ela seria fundamental, é outro dado constatado. É o que acontece, por exemplo, na dissertação de ROCHA (1987).

CHAGAS (1989), em sua dissertação, diz que há muitas conceituações de educação sexual, cada uma enfocando um ou mais aspectos, dependendo do marco ideológico em que se situa. Por duas vezes usa o termo "Pedagogia Sexual" (com letra maiúscula) como sinônimo de educação sexual, no entanto, não faz nenhum esclarecimento quanto ao uso da terminologia.

Diz que há dois tipos de educação sexual: a funcional e a intencional. Apesar de não fazer nenhuma referência ao conceito apresentado por Werebe, o primeiro tipo corresponderia ao que esta chama de de educação sexual informal e o segundo, de formal. Sem nenhuma comparação ou questionamento, apresenta, vinte cinco páginas adiante, uma outra classificação dada por COLOMBINO (1989, apud CHAGAS, 1989), segundo o qual há três formas de educação sexual: informal, formal e não-formal.

Embora Chagas não faça paralelo com sua classificação (funcional/intencional) já dada, ou com a classificação feita por Werebe, as duas primeiras formas explicitadas por Colombino, que ela apresenta, corresponderiam às classificações de Werebe, enquanto que a educação sexual não-formal "... ocorre nas associações, grêmios, instituições religiosas, dirige-se a grupos que solicitaram atividade educativa e tem as marcas da ideologia" (COLOMBINO, apud CHAGAS, 1989, p. 29).

Para efeito de comparação, é interessante citar uma classificação semelhante, quanto aos tipos de educação sexual, encontrados no artigo de periódico de CAVALCANTI (1993). Este autor também apresenta (sem estar neste ponto pautado em nenhum outro teórico) os mesmos três tipos fundamentais que Colombino, conforme acima discorrido. Porém, diferentemente de Colombino (apud CHAGAS, 1989), CAVALCANTI (1993) considera que a "formal" é dada pela escola e a "informal" pela família, pela Igreja e pelos grupos sociais; a "não-formal" corresponde às "... conferências e palestras para grupos interessados mas que não pertencem propriamente ao sistema de ensino". (p. 169)

Vê-se então que, apesar da classificação quanto às formas de educação serem iguais, nos dois casos acima, a conceituação difere, o que torna o quadro bastante confuso.

Pode-se considerar desnecessário uma classificação em "não-formal", uma vez que a classificação em "formal" é suficiente para abranger toda e qualquer atividade sistemática, intencional, deliberada, independente do ambiente onde ocorra (escola, igreja, associações, etc.) ou da forma como se estrutura (inserida ou não no currículo escolar, como uma disciplina, um batepapo, uma palestra etc)

A preocupação em "esmiuçar" as classificações é pois, além de inútil e desnecessária, uma barreira para a construção de uma linguagem comum e de um corpo sólido de conceitos teóricos.

Tratando agora da questão do uso dos termos educação sexual e orientação sexual, como sinônimos, constatou-se, conforme mostra a Tabela 3, que ocorre em oito dissertações e/ou teses (50\%): ANGELI (1986 e 1992); FERRUA (1980); FIGUEIREDO (1991); FOREMAN (1989); GUIMARÃES (1989); MATANÓ (1990) e NERY (1982).

GUIMARÃES (1989) e NERY (1982), além de usarem esses dois termos-chaves, acrescentam mais um como sinônimo: informação sexual. FIGUEIREDO (1991) acrescenta: instrução sexual.

\footnotetext{
2 Werebe (1981) opta pela terminologia educação sexual e a classifica em dois tipos: informal (processo global, não intencional) e formal (ação deliberada). (Mais adiante, neste artigo, esses conceitos serão explicados de forma mais completa).
} 
Apesar de usar os termos como sinônimos, Foreman e Guimarães usam mais predominantemente o termo educação sexual, enquanto Figueiredo, Nery e Matanó usam orientação sexual com muito predomínio.

No caso desta última autora, ao referir-se ao projeto da rede municipal de São Paulo, que é o foco central de toda sua análise, usa o termo orientação sexual. Já na parte introdutória de sua dissertação, quando tenta reconstituir a história da educação sexual no Brasil, usa esta última terminologia.

Na verdade, tanto a reconstituição histórica, quanto o próprio projeto da rede dizem respeito à educação sexual formal, sistemática e, portanto, em ambos os casos, é cabível o termo educação sexual.

Como o projeto (da rede municipal) analisado por MATANÓ (1990) tem em seu título oficial o termo orientação sexual, acredita-se que, em certo sentido, a autora tenha sido coerente ao usar esse termo. No entanto, apesar da coerência, permanece na Dissertação de Matanó um hiato entre as duas terminologias: de um lado, a "educação sexual" no Brasil: reconstituição histórica e de outro, a "orientação sexual": o Projeto de Orientação Sexual da Rede Municipal de Ensino de São Paulo.

Evidentemente, isto não afetou a essência do trabalho, e, principalmente, a relevância social do mesmo, mas é um exemplo claro da diçotomia na conceituação da educação sexual.

Do conjunto de autores de dissertações e/ou teses que usam educação sexual e orientação como sinônimos, apenas Angeli, em sua Dissertação de 1986 e em sua Tese de 1992, procura diferenciar os termos. Para ela, educação sexual ocorre no lar e orientação sexual (que considera uma atividade deliberada) pode ocorrer no lar e ou na escola. Apesar dessa diferenciação, acaba usando várias vezes o termo educação sexual para referir-se ao trabalho feito pela escola.

Portanto, à semelhança do que foi encontrado em alguns artigos de periódicos e livros, também em dissertações e/ou teses vem ocorrendo o uso dos termos-chaves de forma confusa, no sentido de não estar em coerência com as definições dadas pelo próprio autor em seu texto.

Retomando o quadro geral do uso das terminologias nas dissertações e/ou teses, temos a seguinte situação: em 43,35\% (sete) o termo educação sexual é usado de forma exclusiva; em $50 \%$ (oito) os termos educação sexual e orientação sexual são usados como sinônimos. Deste último conjunto, duas publicações (a de FOREMAN, 1989 e a de GUIMARÃES, 1989) usam educação sexual com predomínio. Se somarmos essas duas, ao conjunto das que usam exclusivamente educação sexual, a percentagem da opção por este último termo eleva-se de $43,75 \%$ para $56,25 \%$
O termo orientação sexual não é usado de forma exclusiva em nenhuma dissertação ou tese; porém é usado com predomínio em três: ANGELI, 1986 e 1992 e NERY, 1982.

Pode-se então afirmar que, assim como nos artigos de periódicos e nos livros, não há também uma padronização quanto ao uso da terminologia básica, bem como quanto à classificação dos tipos de educação sexual, nas publicações acadêmico-científicas (dissertações e teses), que espera-se, constituem-se em produção de maior peso para o avanço da ciência.

É curioso registrar a estranheza que causa a visualização, num índice de dissertação, da falta de padronização no uso das terminologias. No caso, por exemplo de FERRUA (1980), o título de um dos capítulos é: "Organização de um curso de educação sexual para adolescentes", enquanto que num dos itens do mesmo capítulo, encontramos; "Terceira fase: curso de orientação sexual".

Peculiar também é a situação onde o autor, ao transpor para seu texto a idéia de outros autores, faz "tábula rasa" da terminologia usada no texto consultado e conecta as idéias dos autores, ao termo de sua opção (orientação sexual). Assim ocorreu, por exemplo, num artigo de periódico (GHERPELI et al., 1992), onde são citadas idéias de BRUSCHINI e BARROSO (1986), que adotam, na verdade, o termo educação sexual.

Não resta dúvia de que é necessário que se busque unificar as terminologias usadas, para uma solidificação do corpo teórico da temática em questão, devendo-se, portanto, por fim ao uso dos sinônimos: orientação, instrução, informação, aconselhamento (sexuais), além de outros.

Na análise da produção científica sobre Educação Sexual no Brasil, encontramos já nos primeiros passos dados na direção da construção de um conceito de educação sexual, a contribuição de Werebe, em seu livro publicado em 1977. Neste livro, a autora apresenta uma associação dos termos educação sexual e informação sexual. Para ela, essas duas ações, na prática, estão indissociavelmente ligadas e "... informar é também educar e é impossível delimitar as fronteiras entre estas ações e, conseqüentemente, determinar quando e onde pára a informação sexual para começar a educação". (WEREBE, 1977, p. 10).

Logo a seguir, ainda na Introdução, diz que "preferiria" [grifo nosso] empregar ao longo do livro o termo educação sexual "... nela incluindo a informação sexual como uma das modalidades dessa educação", mas que decidiu conservar a expressão informação sexual "... para facilitar a inteligência [inteligibilidade?] do texto". (WEREBE, 1977, p. 11)

Assim, acaba por usar ao longo de todo o seu 
livro, na grande maioria das vezes, a expressão: "informação e educação sexuais". Diz que "a expressão informação sexual é correntemente utilizada para designar a comunicação de conhecimentos sobre a sexualidade". (WEREBE, 1977, p. 11)

Já em seu texto de 1981, Werebe usa tão somente terminologia educação sexual, o que torna possível crer que tenha reconhecido a supremacia desta, como também que a mesma prescinde do termo informação. Classifica a educação sexual em dois tipos:

- "a educação sexual informal, processo global, não intencional, que engloba toda ação exercida sobre o indivíduo, no seu cotidiano, desde o nascimento, com repercussão direta ou indireta sobre sua vida sexual;

- a educação sexual formal, deliberada, institucionalizada, feita dentro ou fora da escola." (WEREBE, 1981, p. 106).

Também em seu livro de 1977, apresentava esta classificação, apenas com uma variação: ao invés de denominar de "informal", referia-se à educação sexual tomada num sentido amplo e ao invés de "formal", à educação sexual num sentido mais restrito. No "corpus", analisado neste trabalho, constatou-se que um número significativo de autores adere, explícita, ou implicitamente, à conceituação fornecida por WEREBE (1981), que pode ser considerada útil e válida, como uma conceituação a ser adotada pelos teóricos dessa área do conhecimento.

O termo educação sexual é mais adequado, na medida em que abre espaço para que a pessoa que aprende seja considerada como sujeito ativo do processo de aprendizagem e não mero receptor de conhecimentos e/ou de orientações, como sugerem as outras terminologias: orientação, informação, instrução... Estas últimas denotam destaque na ação do professor.

VITIELLO (1994), após definir cada um dos vários sinônimos, fecha de maneira brilhante a questão, ao dizer que:

"educar, embora possa passar por informar, por orientar e por aconselhar, é mais do que a soma dessas partes isoladas (...) significa "formar", (...) na acepção de que o educador dá ao educando condições e meios para que cresça interiormente..." (p. 203)

Além de tudo, educação sexual é um termo que está em consonância com as estratégias consideradas fundamentais nesse processo, quais sejam: "debate aberto", discussões e educação através da participação em lutas sociais.

Para reforçar a posição de que a padronização da terminologia é necessária e que, educação sexual é o termo que deve ser priorizado, é útil tomarmos conhecimento de algumas conceituações ou comentários, encontrados nos textos que compõem o "corpus", para as terminologias usadas como sinônimos.

Quanto ao termo orientação sexual, CAVALCANTI (1993) diz que existem "... três orientações sexuais diferentes: a homossexual, a heterossexual e a bissexual". (p. 40)

SUPLICY (1987) diz que a "... a orientação sexual significa a expressão sexual de cada indivíduo por um membro de outro sexo, do mesmo sexo, ou por ambos os sexos". (p. 266)

Também SORJ (1992) usa o termo orientação sexual para referir-se ao homossexualismo e ao heterossexualismo.

Nesta mesma linha de pensamento, temos o pesquisador da homossexualidade, o antropólogo Dr. Luiz Mott, que além de estudar e publicar sobre o assunto, é um dos grandes batalhadores contra a opressão a que estão sujeitos os homossexuais. MOTT (1996) informou que, na Constituição dos Estados de Sergipe, Mato Grosso e Distrito Federal, o direito à liberdade de orientação sexual, no sentido de poder ser homo, hetero ou bissexual, está incluído entre os direitos humanos. Acrescentou que este termo está presente - com este mesmo sentido - em setenta e três leis orgânicas municipais.

Já KEHL (1981) usa o termo orientação sexual (diferenciando-o de educação sexual) para referir-se à "... sexologia como modelo de orientação sexual para adultos". (p. 103). Então, para ela, esse termo é aplicado ao trabalho do orientador e do terapeuta sexual, cujo objetivo é divulgar técnicas que vão dirigir e orientar a sexualidade para uma vida sadia e equilibrada.

Quanto ao tempo informação sexual, além de sugerir a passividade do sujeito que aprende, a limitação e inadequação do termo são reforçadas pelo apontamento de Barroso (apud FERRUA, 1980), de que o limitar-se apenas à transmissão de informações é uma das formas de educação anti-sexual.

Considerando a miscelânea de terminologias e classificações usadas, é possível afirmar que essa área do conhecimento está deficitária em um dos pontos de sua estrutura básica: no da elaboração de uma linguagem comum, no que concerne especificamente à terminologia básica e à classificação do processo (educação sexual) em si.

Finalmente, vale ressaltar que, para um avanço substancial de um conjunto teórico de conhecimentos, é imprescindível que se parta do que já foi construído na área; no caso aqui em questão: que se parta dos conceitos já elaborados. O que não significa, evidentemente, que se deva conservá-los de maneira acrítica, mas sim que sejam tomados como ponto de referência para novas conceituações, quando essas se fizerem necessárias, ou mesmo quando se deseja propor novas conceituações. 
FIGUEIRÓ, M.N.D. Sexual Education: Problems of conceptualization and basic terminology adopted in the brasilian academic and scientific production. Semina: Ci. Sociais/Humanas, Londrina, v. 17, n. 3, p 286-293, Sep. 1996.

ABSTRACT: Aiming at working out in detail the state of knowledge of the academic and scientific production of Sexual Education in Brazil, during the period comprising 1980 to 1993, the analysis of Dessertations, Theses, books, journal articles and other works presented in scientific events was carried out. One of the goals was to investigate the basic terminology adopted to refer to Sexual Education and the concepts of Sexual Education present in the publications. The lack of pattern for basic terminology as well as the lack of a clear and straightforward theorical position regarding the concept of Sexual Education were detected. Besides, differences, incoherences and/or confusions were also found, in some texts, in the attempts made to classify the types of Sexual Education. Theoretical subsidiaries which lead to uniform and scientifically valid patterning of basic terminology, conceptualization and classification are presented in this work.

KEY-WORDS: Sexual education; sexual education conceptualization; basic terminology; state of the art.

\section{REFERÊNCIAS BIBLIOGRÁFICAS}

ANGELI, Heloísa Aparecida Tiveli. A problemática sexual na adolescência. São Paulo: USP, 1986. Dissertação (Mestrado em Psicologia Escolar). Universidade de São Paulo, 1986. p. 163-194: A educação sexual como profilaxia.

ANGELI, Heloísa Aparecida Tiveli. Comportamento e informação sexual de adolescentes: uma análise psicológica junto a primeiranistas universitários. São Paulo: USP, 1992. Tese (Doutorado em Psicologia Escolar). Universidade de São Paulo, 1992. p. 92-113: Educação sexual.

BARCELLOS, Jorge Alberto Soares. A pedagogia de Eros: territórios, vida cotidiana e saber nos projetos de implantação da educação sexual em Porto Alegre. Porto Alegre: UFRGS, 1992. Dissertação (Mestrado em Educação) - Universidade Federal do Rio Grande do Sul, 1992.

BARROSO, Carmen; BRUSCHINI, Maria Cristina (orgs.). Sexo e juventude: como discutir a sexualidade em casa e na escola. 2. ed. São Paulo: Brasiliense, 1985.

BERGER, Israel. Palestras sobre aspectos da sexualidade para grupos de adolescentes: relato de uma experiência. Revista Brasileira de Sexualidade Humana, São Paulo v. 1, n. 2, p. 102-103, jul/dez. 1990.

BERLER, Lilian Geó Soares (coord.). Texto sobre a implantação da educação afetivo sexual no Sistema Promove de Ensino. Belo Horizonte: Grupo de Educação e Orientação Sexual, 1995. Apostila.

BRUSCHINI, Maria Cristina; BARROSO, Carmen. Educação sexual e prevenção da gravidez. In: BARROSO, Carmen et al. Gravidez na adolescência. Brasília: INPLAN/IPEA/ UNICEF, 1986. p. 29-54. (Série Instrumentos para a Ação ก. 6)

CAVALCANTI, Ricardo da Cunha. Educação sexual no Brasil e na América Latina. Revista Brasileira de Sexualidade Humana, São Paulo, v. 4, n. 2, p. 164-177, 1993.

CHAGAS, Eva Regina Carrazoni. Principais características pessoais e profissionais do educador para a saúde que atua na área de educação sexual: problemática de sua formação. Porto Alegre, PUCRGS, 1989. Dissertação (Mestrado em Educação) - Pontifícia Universidade Católica do Rio Grande do Sul, 1989.

CONCEIÇÃO, Isméri Seixas Cheque. Pelo bem dos filhos de nossos filhos. Dois Pontos, Belo Horizonte, v. 1, n. 4, p. 46-48, jul. 1995.

CONCEIÇÃO, Isméri Seixas Cheque; VITIELLO, Nelson. Educação sexual. Femina, São Paulo, v. 14, n. 10, p. 939 942, out. 1986.

CONCEIÇÃO, Isméri Seixas Cheque. Educação sexual. In: VITIELLO, Nelson et al. Adolescência hoje. São Paulo: Roca, 1988. p. 71-76.

EGRY, Emiko Yochikawa. O docente de enfermagem e o ensino da sexualidade humana: ação educativa através da pesquisa participante. São Paulo, USP, 1985. Tese (Doutorado em Saúde Pública) - Universidade de São Paulo, 1985.

EISENSTEIN, Evelyn et al. Sexualidade na adolescência. In: ZECKER, Israel (org.). Adolescente também é gente. 2. ed. São Paulo: Summus, 1985. p. 180-189.

FELIZARI, Gessi Maria Cardoso. Enfermagem escolar e educação sexual para adolescentes. Rio de Janeiro: UFRJ, 1989. Dissertação (Mestrado em Enfermagem) Universidade Federal do Rio de Janeiro, 1989

FERRUA, Leila Heimburg. Educação sexual: análise crítica de uma experiência. Campinas, PUC, 1980. Dissertação (Mestrado em Psicologia Clínica) - Pontifícia Universidade Católica de Campinas, 1980.

FIGUEIREDO, Tulio Alberto Martins de. Perfil de adolescentes de uma escola pública e suas opinióes em relação à orientação sexual na escola. São Paulo: USP, 1991. Dissertação (Mestrado em Saúde Pública) - Universidade de São Paulo, 1991.

FIGUEIRÓ, Mary Neide Damico. Educação Sexual no Brasil: estado da arte de 1980 a 1993. São Paulo: Universidade Estadual de São Paulo, 1995. Dissertação (Mestrado em Psicologia Escolar) - Universidade de São Paulo, 1995. 
FOREMAN, Valéria Lopes. Importância da educação sexual no desenvolvimento de adolescentes cegos. São Paulo: PUC, 1989. Dissertação (Mestrado em Educação Escolar Brasileira) - Pontifícia Universidade Católica de São Paulo, 1989.

GHERPELLI, Maria Helena Brandão Vilela. Direito ou renúncia à sexualidade? Uma experiência de orientação sexual com jovens limitrofes. Revista Brasileira de Sexualidade Humana, São Paulo: v. 3, n. 2, p. 147-153, 1992.

GHERPELLI, Maria Helena Brandão Vilela; BURALLI, Keiko Ogura; ROSENBURG, Cornélio Pedroso. Proposta de um programa de orientação sexual para escolas infantis e de $1^{\circ}$ e $2^{\circ}$ graus. Revista Brasileira de Sexualidade Humana, São Paulo: v. 3, n. 1, p. 46-55, jan./jun. 1992.

GUIMARÃES, Isaura Rocha Figueiredo. Ilusão e realidade do sexo na escola: um estudo das possibilidades da educação sexual. Campinas: UNICAMP, 1989. Tese (Doutorado em Educação / Metodologia de Ensino) Universidade Estadual de Campinas, 1989.

HENTSCHEL, Heitor. Educação sexual um inquérito. Femina, São Paulo, v. 15, n. 4, p. 290-295, abr. 1987.

KEHL, Maria Rita. Educação sexual: instrumento de democratização ou de mais repressão? Cadernos de Pesquisa, São Paulo, n. 36, p. 99-110, fev. 1981. A autora participou neste trabalho na mesa-redonda apresentada na XXXII Reunião da Sociedade Brasileira para o Progresso da Ciência. Rio de Janeiro, 1980.

LUCA, Laurival A. de. A orientação das adolescentes. In: LUCA, Laurival A. de. O problema sexual da adolescente. Indianópolis; Almed, 19890. p. 97-117.

MATANO, Maria Silvia Cavasin. Orientação sexual: projeto de ação pedagógica da rede municipal de ensino de São Paulo (1978-1982). São Paulo: PUC, 1990. Dissertação (Mestrado em Educação) - Pontifícia Universidade Católica de São Paulo, 1990.

MATARAZZO, Maria Helena; MAZIN, Rafael. Educação sexual nas escolas. São Paulo: Paulinas, 1988.

MENDES, Adilson Miranda. O desenvolvimento sexual segundo Sigmund Freud, com ênfase na importância da educação sexual. Educação Hoje, Palmas, v. 10, n. 1, p. 82-89, jul. 1984.

MOTT, Luiz. Educação Sexual e Homossexualidade. Florianópolis, 16 ago. 1996. Anotações de palestra ministrada no I Congresso Catarinense de Educação Sexual.

NERY, Maria José Gomes da Silva. Sexualidade humana: disfunções sexuais, conhecimentos e atitudes em relação a sexo. Esquema de um curso de orientação sexual. Campinas: PUC, 1982. Dissertação (Mestrado em Psicologia Clínica) - Pontifícia Universidade Católica de Campinas, 1982

ORTH, Edgar. Educação sexual da criança. 13. ed Petrópolis: Vozes, 1991.

PIZZATTO, Marina. Educação sexual da criança. Revista Gaúcha de Enfermagem, Porto Alegre, n. 3, v. 1, p. 51-59, dez. 1981.

RIBEIRO, Paulo Rennes Marçal. Educação sexual além da informação. São Paulo: EPU, 1990.
ROCHA, Elisa Fernandes de Sousa. Educação sexual e telenovela: liberação ou determinismo ideológico? Curitiba: UFP, 1987. Dissertação (Mestrado em Educação) - Universidade Federal do Paraná, 1987.

SÃO PAULO (Estado). Secretaria de Educação. Coordenadoria de Estudos e Normas Pedagógicas. Sexualidade humana: uma abordagem curricular com enfoque educativo. São Paulo; SE/CENP, 1984. v. 1.

SCHUSSEL, Darcy Raiça. Educação sexual: análise de opiniões de diferentes segmentos sociais. São Paulo: PUC 1982. Dissertação (Mestrado em Psicologia da Educação) - Pontifícia Universidade Católica de São Paulo, 1982.

SILVA, Ricardo de Castro e. A educação sexual nas turmas de $5^{\text {a }}$ a $8^{\text {a }}$ série do $1^{\circ}$ grau. In: RIBEIRO, Marcos (org.). Educação sexual: novas idéias, novas conquistas. Rio de Janeiro: Rosa dos Tempos, 1993, p. 177-184.

SORJ, Bila. Relações de gênero e teoria social. In: SEMINÁ RIO DO PROGRAMA DE INCENTIVO E DE FORMAÇÃO EM PESQUISA SOBRE MULHER: Relação de Gênero na Sociedade Brasileira, 1, São Paulo, 1992. Trabalho não publicado, versão preliminar.

SUPLICY, Marta (sup.). Sexo para adolescentes: orientação para educadores. São Paulo: FTD, [1988?].

SUPLICY, Marta. Conversando sobre sexo. 15. ed. Petrópolis: Vozes, 1987.

Papai, mamãe e eu. São Paulo: FTD, 1990.

Educação e orientação sexual. In: RIBEIRO, Marcos (org.). Educação sexual: novas idéias, novas conquistas. Rio de Janeiro: Rosa dos Tempos, 1993. p 21-36.

TAVARES, Celina Araújo. Orientação sexual para crianças e adolescentes: proposta para formação de enfermeiros como educadores sexuais. Revista Paulista de Enfermagem, São Paulo, v. 5, n. 1, p. 8-11, jan./mar. 1985.

VERARDO, Maria Terezinha Vieira. A sexualidade educada: nota crítica sobre pressupostos teóricos e projetos empíricos. Campinas: UNICAMP, 1989. Dissertação (Mestrado em Educação) - Universidade Estadual de Campinas, 1989.

VITIELLO, Nelson. Educação sexual: um inquérito. Femina, São Paulo, v. 15, n. 4, p. 288-290, abr. 1987.

VITIELLO, Nelson. Reprodução e sexualidade: um manual para educadores. São Paulo: $\mathrm{CEICH}, 1994$.

XAVIER, Nilton Leite. Aspectos da educação sexual e do comportamento sexual feminino. Revista Ci. Maternidade, Infância e Ginecologia, Porto Alegre, v. 5 n. 1, p. 41-45, jan./jun. 1985.

WEREBE, Maria José Garcia. A educação sexual na escola. Lisboa: Moraes Editores, 1977.

\section{Educação sexual: instrumento de} democratização ou de mais repressão? Cadernos de Pesquisa, São Paulo. n. 36, p. 99-110, fev. 1981. A autora participou neste trabalho na: mesa-redonda apresentada na $32^{\mathrm{a}}$ reunião da Sociedade Brasileira para o Progresso da Ciência. Rio de Janeiro, 1980. 